\title{
Aneurysm diameter as a risk factor for pretreatment rebleeding: a meta-analysis
}

\author{
Hieronymus D. Boogaarts, MD, ${ }^{1}$ Jasper H. van Lieshout, MD, ${ }^{1}$ Martinus J. van Amerongen, MD, ${ }^{2}$ \\ Joost de Vries, MD, PhD, ${ }^{1}$ André L. M. Verbeek, MD, PhD, ${ }^{3}$ J. André Grotenhuis, MD, ${ }^{1} \mathrm{PhD},{ }^{1}$ \\ Gert P. Westert, PhD, ${ }^{4}$ and Ronald H. M. A. Bartels, MD, PhD ${ }^{1}$
}

Departments of ${ }^{1}$ Neurosurgery, ${ }^{2}$ Radiology, and ${ }^{3}$ Health Evidence; and the ${ }^{4}$ Scientific Institute for Quality of Healthcare $(I Q$ Healthcare), Radboud University Nijmegen Medical Centre, Nijmegen, the Netherlands

OBJECT Aneurysmal rerupture prior to treatment is a major cause of death and morbidity in aneurysmal subarachnoid hemorrhage. Recognizing risk factors for aneurysmal rebleeding is particularly relevant and might help to identify the aneurysms that benefit from acute treatment. It is uncertain if the size of the aneurysm is related to rebleeding. This meta-analysis was performed to evaluate whether an association could be determined between aneurysm diameter and the rebleeding rate before treatment. Potentially confounding factors such age, aneurysm location, and the presence of hypertension were also evaluated.

METHODS The authors systematically searched the PubMed, Embase, and Cochrane databases up to April 3, 2013, for studies of patients with aneurysmal subarachnoid hemorrhage that reported the association between aneurysm diameter and pretreatment aneurysmal rebleeding. The Grading of Recommendations Assessment, Development and Evaluation (GRADE) criteria were used to evaluate study quality.

RESULTS Seven studies, representing 2121 patients, were included in the quantitative analysis. The quality of the studies was low in 2 and very low in 5 . Almost all of the studies used $10 \mathrm{~mm}$ as the cutoff point for size among other classes, and only one used $7 \mathrm{~mm}$. An analysis was performed with this best unifiable cutoff point. Overall rebleeding occurred in $360(17.0 \%)$ of 2121 patients (incidence range, from study to study, $8.7 \%-28.4 \%$ ). The rate of rebleeding in small and large aneurysms was $14.0 \%$ and $23.6 \%$, respectively. The meta-analysis of the 7 studies revealed that larger size aneurysms were at a higher risk for rebleeding (OR $\left.2.56[95 \% \mathrm{Cl} 1.62-4.06] ; p=0.00 ; l^{2}=60 \%\right)$. The sensitivity analysis did not alter the results. Five of the 7 studies reported data regarding age; 4 studies provided age-adjusted results and identified a persistent relationship between lesion size and the risk of rebleeding. The presence of hypertension was reported in two studies and was more prevalent in patients with rebleeding in one of these. Location (anterior vs posterior circulation) was reported in 5 studies, while in 4 there was no difference in the rebleeding rate. One study identified a lower risk of rebleeding associated with posterior location aneurysms.

CONCLUSIONS This meta-analysis showed that aneurysm size is an important risk factor for aneurysmal rebleeding and should be used in the clinical risk assessment of individual patients. The authors' results confirmed the current guidelines and underscored the importance of acute treatment for large ruptured aneurysms.

http://thejns.org/doi/abs/10.3171/2014.12.JNS14931

KEY WORDS subarachnoid hemorrhage; intracranial aneurysm; recurrence; risk; meta-analysis; vascular disorders

$\mathrm{T}$ The incidence of aneurysmal subarachnoid hemorrhage $(\mathrm{SAH})$ is about $5-10$ cases per $100,000 .^{21,26}$ Closure of the aneurysm after initial SAH is the primary goal to prevent aneurysmal rebleeding, which has an associated mortality rate of up to $50 \% .^{32}$ The incidence of rebleeding after an $\mathrm{SAH}$ has been estimated to be $14 \%-$ $17 \%$ during the first 24 hours, and studies have shown that $87 \%-92 \%$ of all rebleeding occurs within the first 6 hours after the initial bleed.9,32 Endovascular coiling or clipping to secure the aneurysm is advised as early after rupture as is feasible to reduce the rate of rebleeding. ${ }^{8}$ Currently, ultra-early treatment, considered to be within 24 hours, is advised for patients in good clinical condition. ${ }^{34}$ Although nonmodifiable causes, such as transfer from other hospitals and late diagnosis, might delay treatment, ultra-early treatment can also be difficult due to internal logistics is-

ABBREVIATIONS GRADE = Grading of Recommendations Assessment, Development and Evaluation; SAH = subarachnoid hemorrhage. SUBMITTED April 25, 2014. ACCEPTED December 1, 2014. 
sues like limited 24/7 surgical coverage and access to operating theaters and anesthetic and nursing staff. ${ }^{34}$

Recognizing risk factors for aneurysmal rebleeding is particularly relevant and might help to identify the aneurysms that benefit from acute treatment. In recent years, several risk factors, such as hypertension and the location and size of the aneurysm, have been shown to be associated with rebleeding. ${ }^{9}, 10,19,28,37$ Biomechanical studies have indicated that cerebral aneurysmal rupture occurs when there is a decrease in the ratio of the artery wall thickness to the radius of the aneurysm. ${ }^{7}$ This concept might explain the possible relationship between aneurysm diameter and the risk of rebleeding. However, the association between the risk of rebleeding and aneurysm size might be confounded by age..$^{28}$ In particular, older patients may have larger aneurysms, and their general condition makes it more likely that treatment is postponed, leaving these individuals more prone to rebleeding. This meta-analysis was performed to evaluate whether an association could be established between aneurysm diameter and rebleeding rate before treatment. Potentially confounding factors like age, aneurysm location, and the presence of hypertension were also evaluated.

\section{Methods}

\section{Search Strategy and Selection Criteria}

The meta-analysis was constructed using the MOOSE guidelines..$^{38}$ In particular, an independent, experienced librarian systematically searched the PubMed, Embase, and Cochrane databases up to April 3, 2013, for studies of patients with aneurysmal SAH that reported the association between aneurysm diameter and pretreatment aneurysmal rebleeding. The search strategy is set out in Table 1.

\section{Data Extraction}

Two authors (J.V.L. and H.B.) independently read all titles and abstracts and selected those that appeared to be relevant for a full text review without language restrictions. Conference abstracts, reviews, meta-analyses, editorials, and animal studies were excluded. From the remaining studies, full-text articles were obtained and independently evaluated by two of the authors (J.V.L. and H.B.). Studies were deemed to be eligible if they included: 1) patients with SAH in either a prospective or retrospective population-based design; 2) the association between aneurysm diameter and the rebleeding rate; and 3) results that included or enabled the calculation of an odds ratio. A third author (R.B.) was consulted to resolve any disagreements. Reference screening was conducted to identify additional studies from the full-text articles that were evaluated. Included studies were selected for a quality review. The methods recommended by the Grading of Recommendations Assessment, Development and Evaluation (GRADE) system for rating the quality of evidence were applied. ${ }^{2,11-17}$ The ORs and 95\% CIs between small and large intracranial aneurysms were extracted or calculated. Size categories were then registered. The cutoff between small and large size had to be established according to the published data. In cases of overlapping cohorts, we excluded the one with the lesser-quality data or, if equal in quality, the one with the fewest patients to prevent an artificial increase in effect size.

\section{Statistical Analysis}

Comprehensive Meta-Analysis software (Version 2.2.046, 2007, Biostat, Inc.) was used to perform statistical analysis. The odds ratio for the risk of the rebleeding of small compared with large intracranial aneurysms was used as the effect size. Size cutoff was determined based on the presence of a (close to) common value across the studies. Both fixed- and random-effect models were used to calculate the summary ORs and 95\% CIs. The significance of the overall OR was determined using a Z-test. For the sensitivity analysis, each study was removed from the total and the remaining studies were reanalyzed. The Type I error was set at 0.05 and the tests were 2 -tailed. We assessed the heterogeneity between the study estimates using the $\mathrm{I}^{2}$ statistic, with thresholds for a low degree of heterogeneity set at $40 \% .{ }^{13}$ The funnel plots were inspected, and the Egger test was used to look for evidence of publication bias.

TABLE 1. Search strategy and results in PubMed, Embase, and Cochrane databases

\begin{tabular}{|c|c|c|c|c|}
\hline \multirow[b]{2}{*}{ Step } & \multirow[b]{2}{*}{ Search Terms } & \multicolumn{3}{|c|}{ No. of Studies } \\
\hline & & PubMed & Embase & Cochrane \\
\hline 1 & $\begin{array}{l}\text { subarachnoid haemorrhage.ti,ab. OR Subarachnoid Hemorrhage[Mesh:noexp] OR (subarachnoid.ti,ab. } \\
\text { AND hemorrhage.ti,ab.) OR subarachnoid hemorrhage.ti,ab. OR subarachnoid haemorrhages.ti,ab. OR } \\
\text { subarachnoid hemorrhages.ti,ab. OR SAH.ti,ab. OR SAHs.ti,ab. OR subarachnoid hematoma.ti,ab. OR } \\
\text { subarachnoid bleeding.ti,ab. OR ((Brain Aneurysm.ti,ab. OR brain aneurysms.ti,ab. OR Cerebral Aneu- } \\
\text { rysm.ti,ab. OR cerebral Aneurysms.ti,ab. OR “Intracranial Aneurysm"[Mesh]) AND (rupture*.ti,ab.))))) †‡ }\end{array}$ & 25,423 & 35,627 & 998 \\
\hline 2 & (“Recurrence”[Mesh] OR Recurrence.ti,ab. OR Recurrences.ti,ab. OR Rebleed”.ti,ab.) & 306,816 & 339,678 & 21,206 \\
\hline 3 & Step $1 \&$ Step 2 & 1844 & 2151 & 75 \\
\hline 4 & $\begin{array}{l}\text { (“Risk”[Mesh] OR Risk.ti,ab. OR sized.ti,ab. OR sizes.ti,ab. OR } 10 \text { mm.ti,ab. OR } 7 \text { mm.ti,ab. OR } 5 \text { mm.ti,ab. } \\
\text { OR } 6 \text { mm.ti,ab. OR } 8 \text { mm.ti,ab. OR } 9 \text { mm.ti,ab. OR diameter.ti,ab.) }\end{array}$ & $1,849,179$ & $2,355,608$ & 111,279 \\
\hline 5 & Step 3 \& Step 4 & 610 & 773 & 25 \\
\hline 6 & Limits: none & 610 & 773 & 25 \\
\hline
\end{tabular}

MeSH = Medical Subject Headings; $\mathrm{mm}$ = millimeter; noexp = no explosion of MeSH heading; ti,ab = title/abstract.

$\dagger$ The asterisk in this field indicates that rupture was a major topic of these articles.

$\ddagger$ Quotation marks indicate that the entire phrase was searched. 


\section{Results}

\section{Included Studies}

The literature search revealed a total of 1408 records: 610 in PubMed, 773 in Embase, and 25 in the Cochrane database (Fig. 1, Table 1). An additional study was found by screening the references. After the removal of duplicates, we were able to identify 867 studies. Review of the abstracts left us with 26 studies for the full-text evaluation. ${ }^{3-6,9,10,18-20,22-25,27-31,33,35-37,39,41}$ Ten studies were excluded because they did not evaluate aneurysm diameter as a risk factor for rehemorrhage rate. 4,6,9,18,22,24,29,36,39,41 Two other articles were excluded because one was a review and the other was an editorial..$^{25,36}$ One study was written in Japanese and was thus also excluded. ${ }^{31}$ Four studies used an overlapping cohort, and the one with most appropriate data was selected. ${ }^{5,19,20,27,28,30,35}$ In total we identified 9 stud-

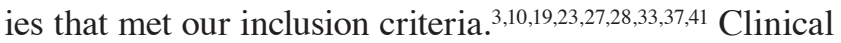
and/or radiological definitions of rebleeding were given in 8 studies and these are listed in Table 2 . Only 1 study reported the median time to rebleeding and the median time to aneurysm repair. ${ }^{3}$ Aneurysm size categories were given in 7 studies, while 2 others reported the mean size for the lesions in the non-rebleeding group compared with the rebleeding group (Table 2). Four studies reported on time to treatment or time to rebleeding (Table 2).

\section{Quality Assessment}

The methodological quality of the 9 included studies was assessed. Of a total of 45 scores, there was no disagreement (Table 3). As a consequence of their observational design, all of the studies started with a maximal quality score of low. None of the studies were rated down based on serious inconsistency, indirectness, imprecision, or publication bias. In 5 studies, however, the quality was rated down because of serious limitations: Adjustment of the rebleeding rate for the time after the initial hemorrhage was not performed, or consecutive series were not reported. ${ }^{10,19,23,33,37}$

\section{Data Analysis}

Seven of 9 studies provided core data, making calculation of the OR possible..$^{10,19,23,28,33,37,41}$ Almost all of the studies used $10 \mathrm{~mm}$ as the cutoff point for aneurysm size among others classes, with only 1 study using $7 \mathrm{~mm}$ (Table 4). An analysis was performed with this best unifiable cutoff point. Overall rebleeding occurred in 360 (17.0\%) of 2121 patients (incidence range, from study to study, $8.7 \%-28.4 \%$ ). The rate of rebleeding in small and large aneurysms was $14.0 \%$ and $23.6 \%$, respectively (absolute risk difference $9.6 \%$ ). The meta-analysis of the 7 studies revealed that larger size aneurysms had an overall OR for rebleeding of $2.32(95 \% \mathrm{CI} 1.77-3.04 ; \mathrm{p}=0.00)$ and an OR of 2.56 (95\% CI 1.62-4.06; $\mathrm{p}=0.00)$ for a fixed- and a random-effect model, respectively (Fig. 2 upper). The results were subject to heterogeneity, which was determined by the $\mathrm{I}^{2}$ statistic to be $60 \%$, indicating that the random-effect

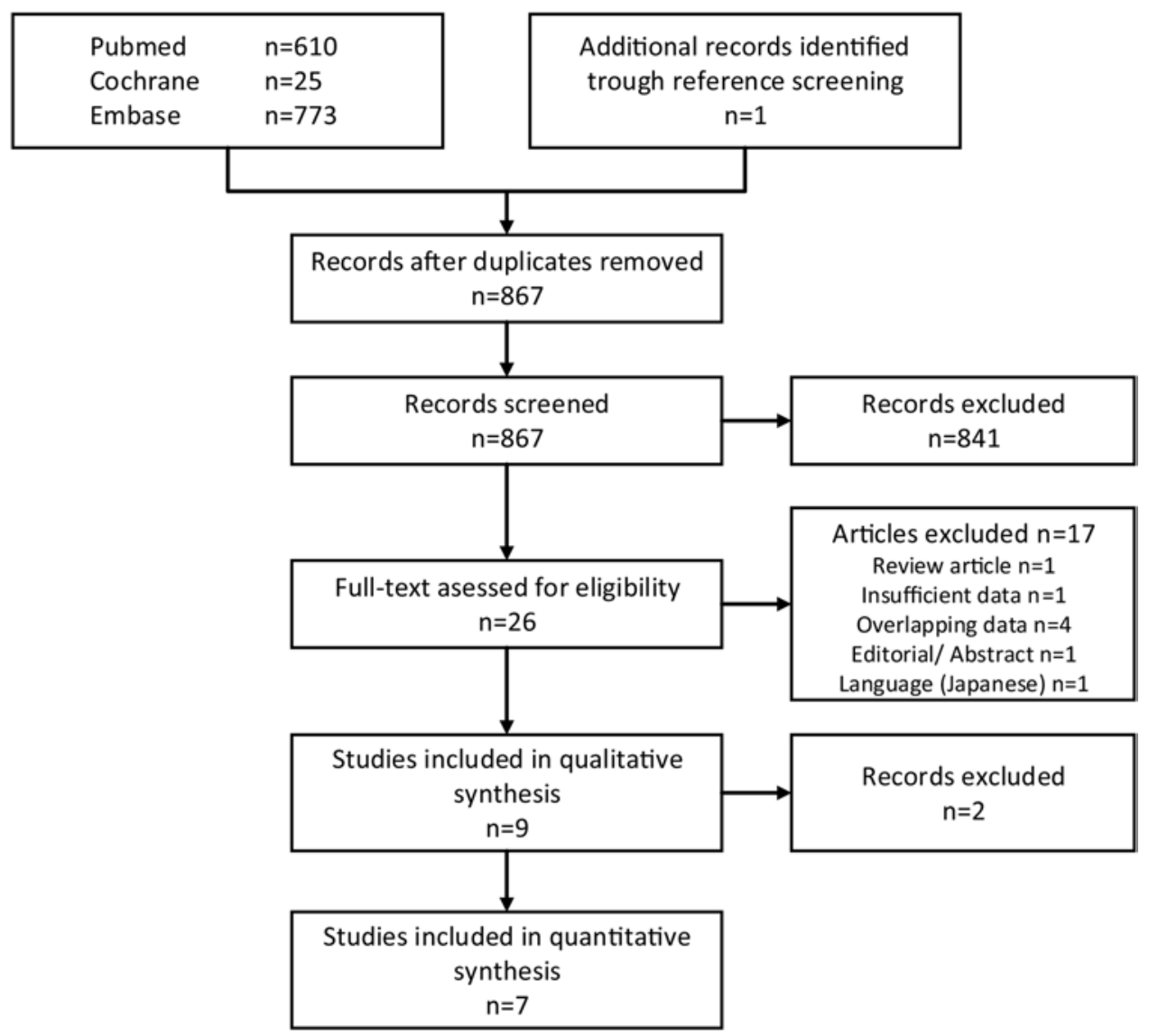

FIG. 1. Chart showing the results of the literature search. 


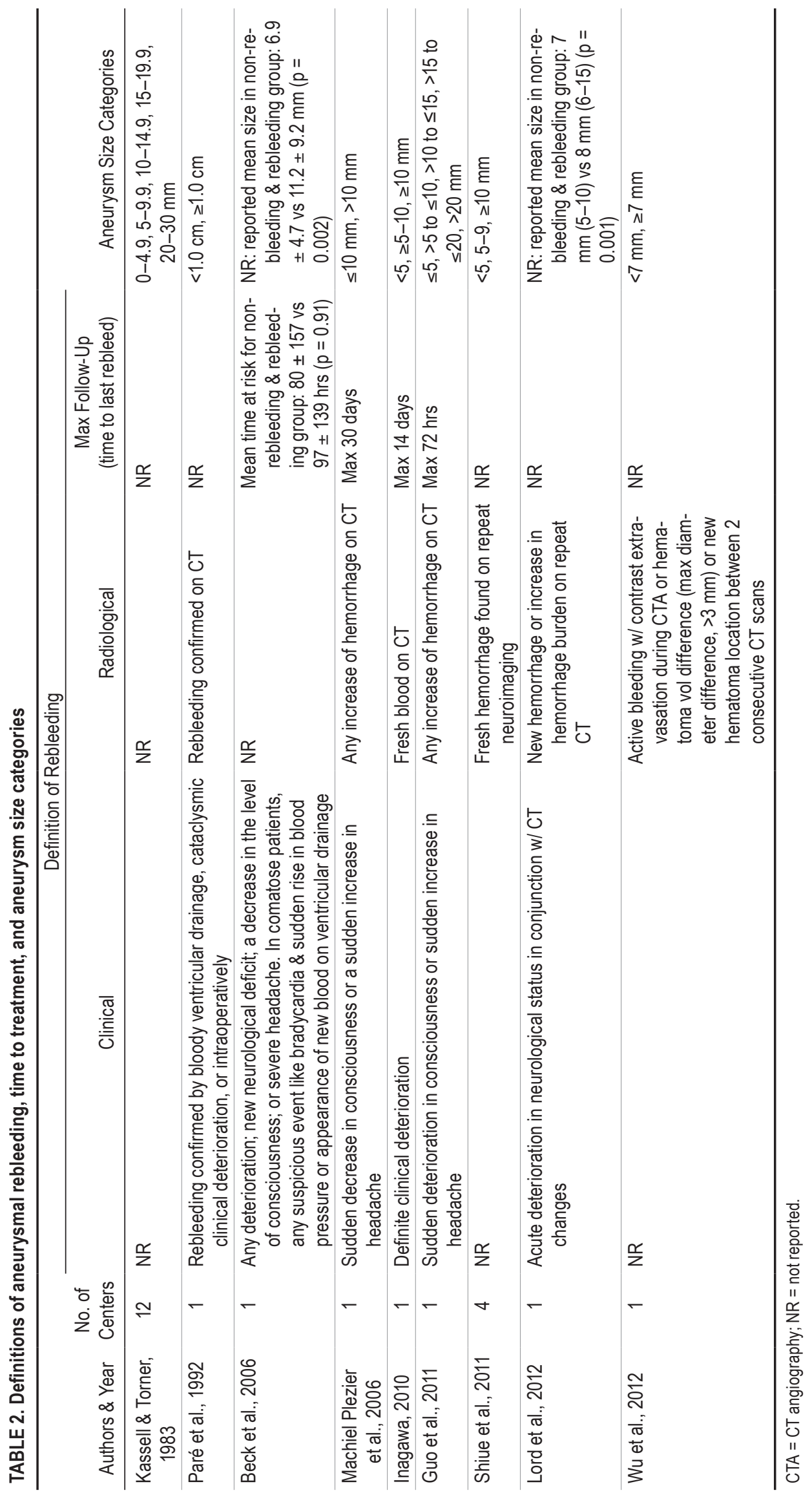


TABLE 3. GRADE quality assessment

\begin{tabular}{|c|c|c|c|c|c|c|c|}
\hline Authors \& Year & Design & Limitations & Inconsistency & Indirectness & Imprecision & $\begin{array}{l}\text { Publication } \\
\text { Bias }\end{array}$ & Quality \\
\hline Kassell \& Torner, 1983 & Observational & Serious & None & None & None & None & Very low \\
\hline Paré et al., 1992 & Observational & Serious & None & None & None & None & Very low \\
\hline Beck et al., 2006 & Observational & None & None & None & None & None & Low \\
\hline Machiel Plezier et al., 2006 & Observational & None & None & None & None & None & Low \\
\hline Inagawa, 2010 & Observational & Serious & None & None & None & None & Very low \\
\hline Guo et al., 2011 & Observational & Serious & None & None & None & None & Very low \\
\hline Shiue et al., 2011 & Observational & Serious & None & None & None & None & Very low \\
\hline Lord et al., 2012 & $\begin{array}{l}\text { Nested case- } \\
\text { control study }\end{array}$ & None & None & None & None & None & Low \\
\hline Wu et al., 2012 & Observational & None & None & None & None & None & Low \\
\hline
\end{tabular}

model is appropriate. The sensitivity analysis did not alter the results (Fig. 2 lower). The funnel plot gave no indication of publication bias, but the findings are of limited value because of the small number of studies considered (Fig. $3)$. The Egger regression test revealed an intercept of 2.3 with a 2-tailed $p$ value of 0.22 , and it was accordingly not statistically significant. Five of the 7 studies reported data on age; 4 studies provided age-adjusted results and identified a persistent relationship between size and the risk of rebleeding. ${ }^{10,19,28,37}$ The presence of hypertension was reported in 2 studies and was more prevalent in patients with rebleeding in 1 of these studies..$^{10,19}$ Location (anterior vs posterior circulation) was reported in 5 studies, while in 4 there was no difference in the rebleeding rate. ${ }^{10,19,33,37,41}$ One study identified a lower risk of rebleeding associated with posterior circulation aneurysms. ${ }^{37}$ These findings provide insufficient evidence to relate hypertension and/or location of the aneurysm with the rebleeding rate.

Only a single study evaluated the risk of rebleeding over time dichotomized for size; the authors found a difference of rebleeding rate within 24 hours that persisted for 3 days after the initial hemorrhage. ${ }^{28}$ They reported a hazard ratio for large aneurysm of 2.4 (95\% CI 1.2-4.5). In another study, median time to aneurysm obliteration did not differ between rebleeding and non-rebleeding groups but was not stratified according to lesion size. ${ }^{3}$

The use of antifibrinolytic agents was reported only by 1 study; the investigators included patients from 1996 to 2011 , and from 2003 on, they used, on a routine basis, aminocaproic acid for all patients before aneurysm clipping or coiling. ${ }^{27}$

Conflicting results have been reported regarding the effect of clinical grade on the risk of rebleeding. Six studies evaluated Hunt and Hess grade as a factor in relation to rebleeding. One study matched for Hunt and Hess grade found a significant difference in aneurysm size in those with rebleeding versus those without rebleeding. ${ }^{27}$ Two studies reported no significant association between Hunt and Hess grade and rebleeding risk. ${ }^{32,40}$ The authors of one study concluded that the larger the aneurysm, the worse was the World Federation of Neurosurgical Societies grade, but did not report it as a independent risk factor. ${ }^{14}$ Two studies found Hunt and Hess grade to be a statistically significant independent risk factor for rebleeding (ORs

TABLE 4. Rebleeding rates

\begin{tabular}{|c|c|c|c|c|c|}
\hline \multirow[b]{2}{*}{ Authors \& Year } & \multicolumn{2}{|c|}{ Aneurysm Size Used for Analysis } & \multicolumn{3}{|c|}{ Rebleeding Rate $(\%)^{*}$} \\
\hline & Small & Large & Small & Large & Total Rebleeding \\
\hline Kassell \& Torner, 1983 & $<10 \mathrm{~mm}$ & $\geq 10 \mathrm{~mm}$ & $49 / 469(10.4)$ & $21 / 195(10.7)$ & $70 / 664(10.5)$ \\
\hline Paré et al., 1992 & $<10 \mathrm{~mm}$ & $\geq 10 \mathrm{~mm}$ & 2/61 (3.3) & 13/67 (19.4) & $15 / 128(11.7)$ \\
\hline Beck et al., 2006 & $\begin{array}{l}\text { NA: reported mean } \\
6.9 \pm 4.7 \text { vs } 11.2\end{array}$ & g \& rebleeding group; & NR & NR & NA \\
\hline $\begin{array}{l}\text { Machiel Plezier et al., } \\
2006\end{array}$ & $\leq 10 \mathrm{~mm}$ & $>10 \mathrm{~mm}$ & $68 / 281(24.2)$ & $22 / 73(30.1)$ & $90 / 354(25.4)$ \\
\hline Inagawa, 2010 & $<10 \mathrm{~mm}$ & $\geq 10 \mathrm{~mm}$ & $48 / 205(23.4)$ & $33 / 80(41.3)$ & $81 / 285(28.4)$ \\
\hline Guo et al., 2011 & $\leq 10 \mathrm{~mm}$ & $>10 \mathrm{~mm}$ & $18 / 169(10.7)$ & $52 / 157(33.1)$ & $70 / 326(21.5)$ \\
\hline Shiue et al., 2011 & $<10 \mathrm{~mm}$ & $\geq 10 \mathrm{~mm}$ & $13 / 195(6.7)$ & $9 / 59(15.3)$ & $22 / 254(8.7)$ \\
\hline Lord et al., 2012 & $\begin{array}{l}\text { NA: reported mean } \\
7 \mathrm{~mm}(5-10) \text { vs }\end{array}$ & $\begin{array}{l}\text { g \& rebleeding group; } \\
\text { 1) }\end{array}$ & NR & NR & NA (case-control study) \\
\hline Wu et al., 2012 & $<7 \mathrm{~mm}$ & $\geq 7 \mathrm{~mm}$ & $5 / 75(6.7)$ & $7 / 35(20.0)$ & $12 / 110(10.9)$ \\
\hline Total & NA & NA & $203 / 1455(14.0)$ & $157 / 666(23.6)$ & $360 / 2121(17.0)$ \\
\hline
\end{tabular}

NA = not applicable.

* The rebleeding rate is the percentage derived by dividing the number of patients with a rebleed by the total number of patients. 


\section{Meta-Analysis: rebleed risk in large vs small aneurysms}

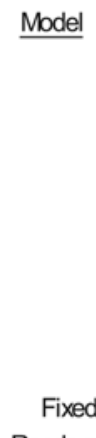

Random
Statistics for each study

$\begin{gathered}\text { Odds } \\ \text { ratio }\end{gathered}$
1.039
7.102
2.430
2.297
4.154
2.520
4.333
2.319
2.562

$\begin{array}{crr}\begin{array}{c}\text { Lower } \\ \text { limit }\end{array} & \begin{array}{c}\text { Upper } \\ \text { limit }\end{array} & \text { Z-Value } \\ 0.603 & 1.792 & 0.138 \\ 1.532 & 32.922 & 2.505 \\ 1.191 & 4.956 & 2.441 \\ 1.325 & 3.981 & 2.962 \\ 2.301 & 7.502 & 4.723 \\ 1.019 & 6.234 & 2.000 \\ 1.243 & 15.104 & 2.302 \\ 1.772 & 3.036 & 6.123 \\ 1.619 & 4.056 & 4.015\end{array}$

Odds ratio and $95 \% \mathrm{Cl}$

$$
\begin{array}{r}
p \text {-Value } \\
0.890 \\
0.012 \\
0.015 \\
0.003 \\
0.000 \\
0.045 \\
0.021 \\
0.000 \\
0.000
\end{array}
$$

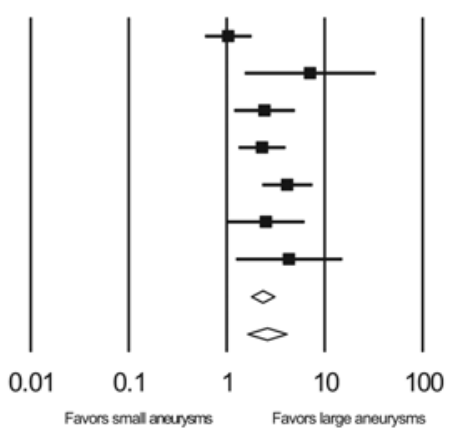

Sensitivity-Analysis: rebleed risk in large vs small aneurysms

$\underline{\text { Model }}$

\section{Study name}

Cumulative statistics

Cumulative odds ratio $(95 \% \mathrm{Cl})$

$\begin{array}{lrrrrr} & \text { Point } & \begin{array}{c}\text { Lower } \\ \text { limit }\end{array} & \begin{array}{c}\text { Upper } \\ \text { limit }\end{array} & \text { Z-Value } & \text { p-Value } \\ \text { Kassel \& Torner, 1983 } & 1.039 & 0.603 & 1.792 & 0.138 & 0.890 \\ \text { Pare et al., 1992 } & 2.364 & 0.367 & 15.237 & 0.905 & 0.366 \\ \text { Machiel Plezier et al., 2006 } & 2.130 & 0.849 & 5.342 & 1.612 & 0.107 \\ \text { Inagawa, 2010 } & 2.069 & 1.130 & 3.790 & 2.354 & 0.019 \\ \text { Guo et al., 2011 } & 2.457 & 1.380 & 4.376 & 3.054 & 0.002 \\ \text { Shiue et al., 2011 } & 2.441 & 1.493 & 3.992 & 3.558 & 0.000 \\ \text { Wu et al., 2012 } & 2.562 & 1.619 & 4.056 & 4.015 & 0.000 \\ & 2.562 & 1.619 & 4.056 & 4.015 & 0.000\end{array}$

Random

4.056

0.000

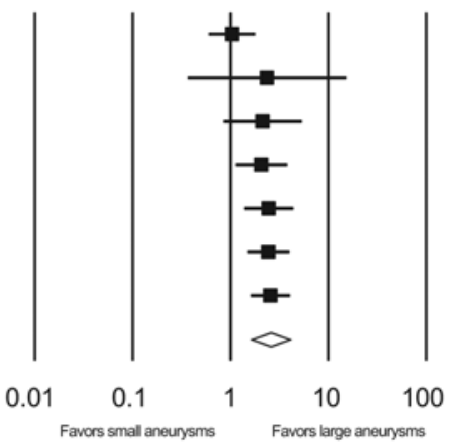

FIG. 2. Forest plots showing results of the meta-analysis of studies reporting rebleeding risk of large versus small aneurysms (upper) and sensitivity analysis (lower). The squares indicate the mean, the whiskers indicate the $95 \% \mathrm{Cl}$, and the diamonds indicate the pooled estimate (the width of the diamond represents the $95 \% \mathrm{Cl}$ ).

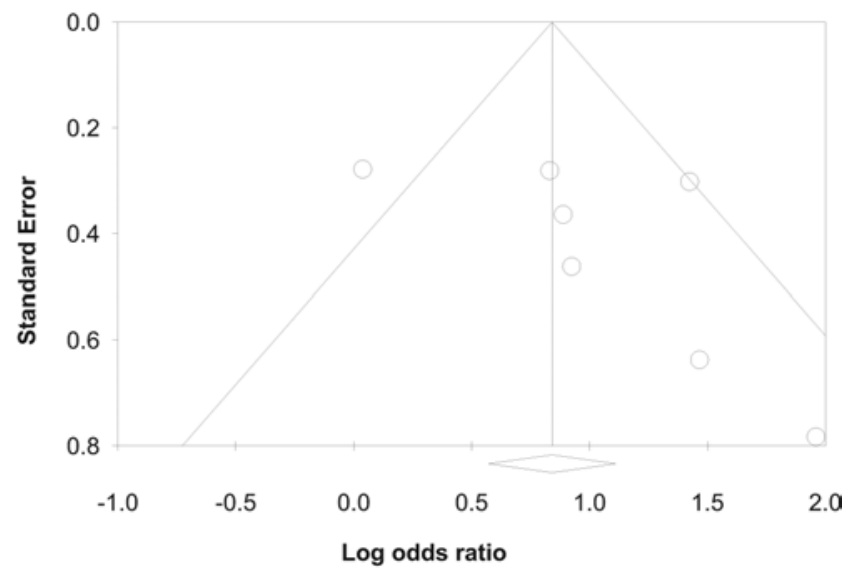

FIG. 3. Funnel plot. The points correspond to the treatment effects from individual studies, the diagonal lines show the expected 95\% confidence intervals around the summary estimate. Odds ratios are plotted on a logarithmic scale.
2.5 and 4.9). ${ }^{5,7}$ Clinical grade at admission is a possible independent risk factor for rebleeding.

\section{Discussion}

The findings of this meta-analysis show that aneurysm size is an important determinant of aneurysmal rebleeding. Age and location are unlikely to be confounding factors. The presence of hypertension was insufficiently registered to determine the role of possible confounding effects. To reduce rebleeding rates, patients with large aneurysms should, when feasible, undergo acute treatment rather than ultra-early treatment, despite possible logistical issues. Additionally, if patients are referred from other centers, or if the diagnosis is delayed, those with large aneurysms still require urgent treatment because it has been shown that the effect size of this association might persist for up to 72 hours after the initial bleed. ${ }^{28}$ An increased risk is seen even within 24 or 48 hours, the time window in which most aneurysm are currently treated. ${ }^{25}$

The results of this analysis for ruptured aneurysms correspond with those of the ISUIA study, in which the pri- 
mary bleeding risk was greater for individuals with larger unruptured aneurysms. ${ }^{40}$

The present research has several limitations. First, there is a potential for publication bias; studies showing no association between aneurysm diameter and rebleeding rate are less likely to be published. The estimated effect size in this meta-analysis could therefore be overestimated. Second, the studies considered did not include data from patients who had died before hospital admission, and this rate would be estimated to be as high as $15 \% .{ }^{26}$ Rebleeding rates during transfer to the hospital were also included and may be as high as $24 \% .^{10}$ Moreover, the average time to hospital admission varied considerably after the initial SAH. Only one study reported median time to aneurysm repair and aneurysm rebleeding..$^{0}$ The research by Machiel Pleizier et al. revealed that there is no significant difference between small and large aneurysms when it comes to the risk of rebleeding 72 hours after the initial SAH. ${ }^{28}$ Third, only one study reported the use of aminocaproic acid. ${ }^{27}$ Although antifibrinolytic therapy does not improve survival or the chance of being independent in activities of daily living, it does reduce the risk of rebleeding by approximately $35 \%$, as indicated in a recent Cochrane review. ${ }^{1}$ Therefore, it is an important factor in rebleeding rate; unfortunately, the published studies did not provide data with which to evaluate the effects of both size and antifibrinolytic therapy together. Fourth, the cutoff for aneurysm size at $10 \mathrm{~mm}$ is artificial and chosen based on the categories set out in the published literature. Fifth, even if rebleeding is prevented in patients with large aneurysms, there is still a substantial rate of rebleeding events (14.0\%) in cases involving small aneurysms. Only the acute treatment of all patients is optimal for prevention of rebleeding. ${ }^{28}$

Hypothetically, acute treatment could be associated with additional treatment risks like increased intraoperative rupture due to the newly formed instable thrombus. However, for treatment within 24 hours, it has been shown that this timeframe was associated with improved clinical outcomes, although the benefit was more pronounced for coiling than clipping. ${ }^{34}$ Moreover, it is unlikely that the risks of acute treatment will accrue in such a way that they outweigh the very high morbidity and mortality rates associated with rebleeding.

\section{Conclusions}

This meta-analysis showed that aneurysm size is an important risk factor for aneurysmal rebleeding and should be used in the clinical risk assessment of individual patients. Our results confirmed the current guidelines and stressed the importance of acute treatment for large ruptured aneurysms.

\section{Acknowledgment}

We would like to thank A. H. J. Tillema for her support with our literature search.

\section{References}

1. Baharoglu MI, Germans MR, Rinkel GJ, Algra A, Vermeulen M, van Gijn J, et al: Antifibrinolytic therapy for aneurys- mal subarachnoid haemorrhage. Cochrane Database Syst Rev 8:CD001245, 2013

2. Balshem H, Helfand M, Schünemann HJ, Oxman AD, Kunz R, Brozek J, et al: GRADE guidelines: 3 . Rating the quality of evidence. J Clin Epidemiol 64:401-406, 2011

3. Beck J, Raabe A, Szelenyi A, Berkefeld J, Gerlach R, Setzer $\mathrm{M}$, et al: Sentinel headache and the risk of rebleeding after aneurysmal subarachnoid hemorrhage. Stroke 37:2733-2737, 2006

4. Bonilha L, Marques EL, Carelli EF, Fernandes YB, Cardoso AC, Maldaum MV, et al: Risk factors and outcome in 100 patients with aneurysmal subarachnoid hemorrhage. Arq Neuropsiquiatr 59 (3-B):676-680, 2001

5. Brilstra EH, Algra A, Rinkel GJ, Tulleken CA, van Gijn J: Effectiveness of neurosurgical clip application in patients with aneurysmal subarachnoid hemorrhage. J Neurosurg 97:1036-1041, 2002

6. Brouwers PJ, Dippel DW, Vermeulen M, Lindsay KW, Hasan D, van Gijn J: Amount of blood on computed tomography as an independent predictor after aneurysm rupture. Stroke 24:809-814, 1993

7. Chaudhry HR, Lott DA, Prestigiacomo CJ, Findley TW: Mathematical model for the rupture of cerebral saccular aneurysms through three-dimensional stress distribution in the aneurysm wall. J Mech Med Biol 6:325-335, 2006

8. Connolly ES Jr, Rabinstein AA, Carhuapoma JR, Derdeyn CP, Dion J, Higashida RT, et al: Guidelines for the management of aneurysmal subarachnoid hemorrhage: a guideline for healthcare professionals from the American Heart Association/American Stroke Association. Stroke 43:1711-1737, 2012

9. Fujii Y, Takeuchi S, Sasaki O, Minakawa T, Koike T, Tanaka R: Ultra-early rebleeding in spontaneous subarachnoid hemorrhage. J Neurosurg 84:35-42, 1996

10. Guo LM, Zhou HY, Xu JW, Wang Y, Qiu YM, Jiang JY: Risk factors related to aneurysmal rebleeding. World Neurosurg 76:292-298, 2011

11. Guyatt G, Oxman AD, Akl EA, Kunz R, Vist G, Brozek J, et al: GRADE guidelines: 1. Introduction-GRADE evidence profiles and summary of findings tables. J Clin Epidemiol 64:383-394, 2011

12. Guyatt GH, Oxman AD, Kunz R, Brozek J, Alonso-Coello P, Rind D, et al: GRADE guidelines 6. Rating the quality of evidence-imprecision. J Clin Epidemiol 64:1283-1293, 2011

13. Guyatt GH, Oxman AD, Kunz R, Woodcock J, Brozek J, Helfand M, et al: GRADE guidelines: 7. Rating the quality of evidence-inconsistency. J Clin Epidemiol 64:1294-1302, 2011

14. Guyatt GH, Oxman AD, Kunz R, Woodcock J, Brozek J, Helfand M, et al: GRADE guidelines: 8 . Rating the quality of evidence-indirectness. J Clin Epidemiol 64:1303-1310, 2011

15. Guyatt GH, Oxman AD, Montori V, Vist G, Kunz R, Brozek J, et al: GRADE guidelines: 5 . Rating the quality of evidence-publication bias. J Clin Epidemiol 64:1277-1282, 2011

16. Guyatt GH, Oxman AD, Schünemann HJ, Tugwell P, Knottnerus A: GRADE guidelines: a new series of articles in the Journal of Clinical Epidemiology. J Clin Epidemiol 64:380-382, 2011

17. Guyatt GH, Oxman AD, Vist G, Kunz R, Brozek J, AlonsoCoello P, et al: GRADE guidelines: 4. Rating the quality of evidence-study limitations (risk of bias). J Clin Epidemiol 64:407-415, 2011

18. Hijdra A, van Gijn J, Nagelkerke NJD, Vermeulen M, van Crevel H: Prediction of delayed cerebral ischemia, rebleeding, and outcome after aneurysmal subarachnoid hemorrhage. Stroke 19:1250-1256, 1988 
19. Inagawa T: Size of ruptured intracranial saccular aneurysms in patients in Izumo City, Japan. World Neurosurg 73:8492,2010

20. Inagawa T, Kamiya K, Ogasawara H, Yano T: Rebleeding of ruptured intracranial aneurysms in the acute stage. Surg Neurol 28:93-99, 1987

21. Ingall T, Asplund K, Mähönen M, Bonita R: A multinational comparison of subarachnoid hemorrhage epidemiology in the WHO MONICA stroke study. Stroke 31:1054-1061, 2000

22. Juvela S: Rebleeding from ruptured intracranial aneurysms. Surg Neurol 32:323-326, 1989

23. Kassell NF, Torner JC: Size of intracranial aneurysms. Neurosurgery 12:291-297, 1983

24. Lanzino G, Kassell NF, Germanson TP, Kongable GL, Truskowski LL, Torner JC, et al: Age and outcome after aneurysmal subarachnoid hemorrhage: why do older patients fare worse? J Neurosurg 85:410-418, 1996

25. Larsen CC, Astrup J: Rebleeding after aneurysmal subarachnoid hemorrhage: a literature review. World Neurosurg 79:307-312, 2013

26. Linn FH, Rinkel GJ, Algra A, van Gijn J: Incidence of subarachnoid hemorrhage: role of region, year, and rate of computed tomography: a meta-analysis. Stroke 27:625-629, 1996

27. Lord AS, Fernandez L, Schmidt JM, Mayer SA, Claassen J, Lee K, et al: Effect of rebleeding on the course and incidence of vasospasm after subarachnoid hemorrhage. Neurology 78:31-37, 2012

28. Machiel Pleizier C, Algra A, Velthuis BK, Rinkel GJ: Relation between size of aneurysms and risk of rebleeding in patients with subarachnoid haemorrhage. Acta Neurochir (Wien) 148:1277-1280, 2006

29. Menon GR, Nair S, Rao RM, Abraham M, Easwer HV, Krishnakumar K: Patterns and predictors of in-hospital aneurysmal rebleed: an institutional experience and review of literature. Ann Indian Acad Neurol 10:247-251, 2007

30. Naidech AM, Janjua N, Kreiter KT, Ostapkovich ND, Fitzsimmons BF, Parra A, et al: Predictors and impact of aneurysm rebleeding after subarachnoid hemorrhage. Arch Neurol 62:410-416, 2005

31. Nemoto M, Yasui N, Suzuki A, Sayama I: [Problems of surgical treatment for multiple intracranial aneurysms.] Neurol Med Chir (Tokyo) 31:892-898, 1991 (Jpn)

32. Ohkuma H, Tsurutani H, Suzuki S: Incidence and significance of early aneurysmal rebleeding before neurosurgical or neurological management. Stroke 32:1176-1180, 2001

33. Paré L, Delfino R, Leblanc R: The relationship of ventricular drainage to aneurysmal rebleeding. J Neurosurg 76:422427, 1992

34. Phillips TJ, Dowling RJ, Yan B, Laidlaw JD, Mitchell PJ:
Does treatment of ruptured intracranial aneurysms within 24 hours improve clinical outcome? Stroke 42:1936-1945, 2011

35. Roos EJ, Rinkel GJ, Velthuis BK, Algra A: The relation between aneurysm size and outcome in patients with subarachnoid hemorrhage. Neurology 54:2334-2336, 2000

36. Rosenørn J, Eskesen V, Schmidt K, Rønde F: The risk of rebleeding from ruptured intracranial aneurysms. J Neurosurg 67:329-332, 1987

37. Shiue I, Arima H, Hankey GJ, Anderson CS: Location and size of ruptured intracranial aneurysm and serious clinical outcomes early after subarachnoid hemorrhage: a populationbased study in Australasia. Cerebrovasc Dis 31:573-579, 2011

38. Stroup DF, Berlin JA, Morton SC, Olkin I, Williamson GD, Rennie D, et al: Meta-analysis of observational studies in epidemiology: a proposal for reporting. JAMA 283:2008-2012, 2000

39. Takagi T, Takayasu M, Suzuki Y, Yoshida J: Prediction of rebleeding from angiographic features in vertebral artery dissecting aneurysms. Neurosurg Rev 30:32-39, 2007

40. Wiebers DO, Whisnant JP, Huston J III, Meissner I, Brown RD Jr, Piepgras DG, et al: Unruptured intracranial aneurysms: natural history, clinical outcome, and risks of surgical and endovascular treatment. Lancet 362:103-110, 2003

41. Wu TC, Tsui YK, Chen TY, Lin CJ, Wu TC, Tzeng WS: Rebleeding of aneurysmal subarachnoid hemorrhage in computed tomography angiography: risk factor, rebleeding pattern, and outcome analysis. J Comput Assist Tomogr 36:103-108, 2012

\section{Author Contributions}

Conception and design: Boogaarts. Acquisition of data: Boogaarts, van Lieshout. Analysis and interpretation of data: Boogaarts, van Lieshout, van Amerongen, Bartels. Drafting the article: Boogaarts, van Lieshout, Westert. Critically revising the article: Boogaarts, van Amerongen, de Vries, Verbeek, Grotenhuis, Westert, Bartels. Reviewed submitted version of manuscript: Boogaarts, van Amerongen, de Vries, Grotenhuis, Westert. Approved the final version of the manuscript on behalf of all authors: Boogaarts. Statistical analysis: Boogaarts, Verbeek. Study supervision: Grotenhuis, Bartels.

\section{Correspondence}

Hieronymus D. Boogaarts, Department of Neurosurgery, Radboud University Nijmegen Medical Centre, Geert Grooteplein Zuid 10, 6500HB, Nijmegen, the Netherlands. email: h.boogaarts@nch.umcn.nl. 